\title{
Trend in the G.C.E. Ordinary Level mathematics performance of students in the North West region of Cameroon.
}

\author{
Anta Akuro* Anyaegbunam Ngozi, Ph.D \\ Faculty of Education, Department of Science Education, Measurement \& Evaluation, University of Nigeria, \\ Nsukka, Enugu State, Nigeria \\ * E-mail of the corresponding author: akuroanta00@gmail.com
}

\begin{abstract}
This work seeks to portray the trend (pattern) in the General Certificate of Education (GCE), Ordinary Level mathematics performance of secondary school students of the North West Region of Cameroon, across the years 2007-2013. To achieve this, an expost facto research design was used. Furthermore, the population of the study was all the 171,187 Form Five secondary school students of the North West Region of Cameroon that sat for this examination across the years 2007-2013. No sampling was used since the results of all the students in the population were considered in the study. The instrument for data collection was the "North West Region Students' GCE O'Level Mathematics Results" Data CD which was officially collected from the headquarters of the Cameroon GCE Board, Buea. Moreover, students' mean mathematics performance for the various years was used to describe the trend in the students' performance. Though the results did not show any systematic pattern, it was noticed that 2009 showed the best mathematics performance, with performance dropping steadily across the years 2011-2013.
\end{abstract}

Keywords: mathematics achievement, performance trend, secondary education, GCE Ordinary Level

\section{Introduction}

Cameroon is a bilingual country with the North West Region being one of the two Anglophone regions of the country. The educational system in this English speaking region is a 6-5-2-3 system with children spending six years at the primary school; five years at the secondary school; two years at the high school; and three years at the university to earn a First Degree.

At the end of their five year program, Anglophone secondary school students take the General certificate of Education, Ordinary Level (also known as the GCE O'Level) examination. This is a standardized certification examination taken by all Anglophone Form Five secondary school students of the country.

The GCE O'Level examination is a British-inherited certification examination system that is still used by Boards in the United Kingdom, and in some Commonwealth countries like Cameroon. Since this examination is a standardized examination, it implies that it is prepared by experts and is subjected to rigorous trial testing and scrutiny. Consequently, the results command high validity and reliability.

With the gaining of Independence and the exit of the colonial powers, in 1976 the General Certificate of Education, London tradition was handed down from London to the Ministry of National Education, Yaoundé (Ngangeh, 2007). However, the control of the examination became plagued by several difficulties and irregularities. These irregularities became more alarming and degenerating every passing year and ranged from poor printing, wrong pagination, wrong spellings, shortage of question papers and materials, late arrival of question papers at the examination centers, wrong instructions, non-respect of published timetables and examination leakages (Mbong, 2009). The conduct of the examination degenerated to a crisis point that the situation could not be ignored. This led the Cameroon Parents'/Teachers' Association of Cameroon (CAPTAC) to clamor for the creation of an examination body which was expected to bring sanity into the conduct of the General Certificate of Education examination.

As a result of these cries and pleas, a Presidential Decree and Text of Application of October 12, 1993 was issued creating the body to be known as the Cameroon GCE Board. It is a para-public establishment of an administrative nature and is placed under the tutelage of the Honorable Minister of Secondary Education. The mission of the examination as completed by the Prime Minister's Order of $12^{\text {th }}$ October 1993 is to organize the following examinations:

- The General Certificate of Education, Ordinary Level (General Subjects)

- The General Certificate of Education, Advanced Level (General Subjects)

- The General Certificate of Education, Ordinary Level (Technical Subjects)

- The General Certificate of Education, Advanced Level (Technical Subjects)

(Cameroon GCE Board, 2011)

The scope of the GCE Board was limited to GCE examinations only. However, when language crisis characterized the Baccalaureate Technique Examinations and other related examinations, with poor translations of papers from French to English being common place, the result being massive failure of Anglophone 
candidates, on $5^{\text {th }}$ March 1997, the Presidential Decree of July 1993, was expanded to cater for Anglophone students in Lycée Techniques (Mbong, 2009). The Board has been waxing strong and now also takes charge of the "Baccaleaureat Technique", "Brevet de Technicien", "Brevet d'Etudes Professionnelles" and the "Brevet Professionelle" (which are all foreign examinations).

At the GCE O'Level examination, Mathematics is one of the subjects that is considered to be very important. This is why this subject has been made compulsory to all students taking the examination. In today's scientific and technological age, for any nation to meet up with the current global challenges, it needs to consider the study of mathematics very seriously. Mathematics can be seen to be greatly related to human development and advancement especially due to its numerical and symbolic nature. Moreover, mathematics as a subject encompasses almost all fields of human life. This can be seen in the fact that the social, economic, political, geographic, scientific, as well as, the technological aspects of man are centered on numbers. This is even most predominant and unavoidable in areas like statistics, accounts, arithmetic and engineering. Mathematics can therefore be seen as the language used to describe the problems arising in most branches of science and technology. It is therefore an encompassing subject that according to Onoshakpoiye (2010), "every human being needs in order to be able to function effectively in day-to-day activities".

Given this great importance of Mathematics, it is very important to assess the nature of trends that have existed in the Mathematics performance of students. Moreover, there have been growing concerns amongst educational researchers at assessing not just the existing performance of students; but in going back into the past to assess trends that have existed in the performance of these students across a period of time. (Kellaghan \& Greaney, 2004). This increase reflects in a growth in interest at assessing and evaluating the outcomes of Education (that is, what students actually learn) to complement the long standing practice of monitoring inputs to the educational process - like physical facilities, curricular materials, teacher training and student participation rates. It further shows an extension of the focus of educational assessment and evaluation from the appraisal of individual student performance to appraising the performance of systems of education, or clearly defined parts of these systems. (Kellaghan \& Greaney, 2001b). The aim of this has been simply to clearly portray patterns in students' performance and to know whether with the passage of time, student performance has been improving, worsening or even remaining constant. Consequently, such information is critical to education policy makers and other stakeholders as to the formulation of policies and measures that could either improve or maintain students' performance. As concluded by Willett (1997: 327), "by measuring change over time, it is possible to map phenomena at the heart of the educational enterprise."

\section{Studies on trends in students' academic performance}

Affrasa and Keeves (1999) investigated changes in students' mathematics achievement in Australian lower secondary schools over time. They analyzed and scaled mathematics achievement data over time by applying the Rasch model using the QUEST (Adams \& Khoo, 1993) computer program. The mathematics achievements of the students were brought to a common scale. This common scale was independent of both samples of students tested and the samples of items employed. The scale was then used to examine the changes in mathematics achievement of students in Australia over 30 years from 1964 to 1994 . Conclusions were drawn as to the robustness of the common scale and the changes in students' mathematics achievements over time in Australia. To do this, they used three different data sets and from these three data sets, two groups of students were compared. The first comparison was between 13-year-old government school students in five states (A, B, C, D and $\mathrm{E}$ ). The results of the comparison revealed that only State $\mathrm{C}$ showed improvement in mathematics achievement over the 14-year period. However, the improvement was not statistically significant. Furthermore, no achievement difference was found in State E while mathematics achievement showed a decline in State A, State B and State D. Among the three states a significant decline was found only in State D. When the overall Australian students' performance was compared, the mathematics achievement level of the 13-year-old students declined over the 14-year period. Similarly in this study, the general mathematics performance of students of the North West Region of Cameroon steadily declined from the year 2011 to 2013.

In the United States, Konstantopoulos (2006) investigated school effects on student academic achievement and determined how these effects changed over time from 1972 to 1992. Data was used from three rich surveys spanning 20 years that queried nationally representative samples of high school seniors: The National Longitudinal Study of the High School Class of 1972 (NLS:72), High School and Beyond first followup from 1982 (HSB:82), and the 1992 second follow-up of the National Educational Longitudinal Study of the Eighth Grade Class of 1988 (NELS:92). Specifically, the female, race, and social class regression coefficients and their variance components estimates were regressed on year of survey. Meta-analytic methods were also used to determine linear trends in the achievement gap and the between-school variation over time. The results from the trend analyses showed that in mathematics, the female gap became smaller over time by about $2 / 3$. Still, it was significant, favoring males in 1992. The race gap decreased by somewhat less than $50 \%$, but it was still 1/3 of an SD (standard deviation) in 1992. The socio-economic status (SES) gap became slightly larger over time. 
All trends were significant and positive. In reading, the gender gap favoring females increased by more than 4 times. The race gap, as in mathematics, decreased significantly over time by $40 \%$, but it still was nearly $1 / 3$ of an SD (standard deviation) in 1992. The SES gap increased over time, as in mathematics. In science, the gender gap remained the same, the race gap decreased, and the SES gap increased.

For international studies that have assessed trends of students' academic performance with time, the TIMSS (Trends in Mathematics and Science Study) is one of the most popular. TIMSS is a project guided by International Association for the Evaluation of Educational Achievement (IEA), and is directed by the TIMSS \& PIRLS (Progress in International Reading Literacy Study) International Study Center. TIMSS (Trends in International and Science Study) was the first global assessment of mathematics and science to provide data about trends over time, measuring achievement in these subjects every four years at the fourth and eight grades. TIMSS is conducted on a 4-year-cycle base (in 1995, 1999, 2003, 2007, 2011, and with planning underway of 2015) (Ker, 2013). TIMSS collects data from students, teachers, and school principals. Information includes the educational contexts such as gender performance, students' background, home environment, students' attitudes toward learning, school facilities, educational support, resource availability, curriculum and instructional approaches, and teacher preparation in teaching. TIMSS 2011 involved more than 60 countries with 600,000 students assessed. In TIMSS at the fourth grade, 17 countries have data measuring trends in mathematics and science achievement over a 16 year period from 1995 to 2011. Indeed, since 1995, 12 of these countries have raised their levels of average mathematics achievement: Australia, England, Hong Kong, Iran, Japan, Korea, New Zealand, Norway, Portugal, Singapore, Slovenia, and the United States. Only three countries had decreases in mathematics since 1995. Eight countries raised their level of science achievement since 1995: Hong Kong, Hungary, Iran, Japan, Korea, Portugal, Singapore and Slovenia. Just one country showed a decrease in science achievement. On the other hand, at the $8^{\text {th }}$ grade in TIMSS, 25 countries have trend data spanning from 1995 or 1999 to 2011. Of these 25 countries, nine have increases in mathematics achievement: Chile, Chinese Taipei, Hong Kong, Italy, Korea, and Lithuania (Ker, 2013). Similarly, the Program for International Student Assessment (PISA) is a worldwide evaluation of 15-year-old school pupils' scholastic performance, performed first in 2000 and repeated every three years. It is coordinated by the Organization for Economic Co-operation and Development (OECD), with the view a view to improving educational policies and outcomes (Wu, 2003). Unfortunately, most of these international student assessment studies do not involve developing countries, worse still considering the case of Cameroon.

\section{Methodology}

In order to carry out the study, an expost facto research design was used since the data on students' mathematics performance already pre-existed the study. The population consisted of all the 171,187 Form Five secondary school students of the North West Region of Cameroon who sat for this examination across the years 2007-2013. All the results for these students were used implying there was no sampling. The instrument for data collection was the "North West Region Students' GCE O'Level Mathematics Results" Data CD which was officially collected from the headquarters of the Cameroon GCE Board, Buea. The data CD contained information on the grades, school type and gender of the students who took the examination for the various years. This instrument was validated by two Measurement and Evaluation experts and it was considered reliable especially as the GCE O'Level is a standardized examination (that is, the examination is prepared by experts, subjected to rigorous trial testing, administered and scored in a consistent manner). Moreover, students' mean performances for the various years were used to describe the trend in students' performance. In doing the statistical analysis, an A-grade was assigned the value of 6 , a B-grade the value of 5, a C-grade the value of 4, a D-grade the value of 3, E-grade the value of 2, F-grade the vale of 1 , and an X-grade the value of 0 . A means plot was used to display the general trend in students' mathematics performance from 2007-2013; while a bar chart was used to display this trend with respect to gender.

\section{Result and discussion}

Figure 1 shows how the mean of the grades of the GCE ordinary level mathematics performance of secondary school students of the North West region of Cameroon changed across the years 2007 to 2013. In the year 2007, the mean of the grades of the students' mathematics performance was 1.539; in the year 2008, it was 1.459; in the year 2009, it was 1.666; in the year 2010, it was 1.520; in the year 2011, it was 1.609 ; in the year 2012, it was 1.477; and in the year 2013, the mean of the grades of the students' mathematics performance was 1.455.

The results show that there was no specific pattern for the mathematics performance of the students across the years 2007 to 2013. The best student mathematics performance across these years was in the year 2009 and this was followed by the year 2011. The worst performance was in the year 2013, followed by the year 2008. It is very important to note that for the last three years, the students' mathematics performance at the GCE ordinary level kept dropping steadily so much so that, the performance in the year 2013 was the lowest across the seven year period. Furthermore, Figure 2 is a bar chart which displays this trend with respect to student gender. From 
this result, it is clearly portrayed that the boys always had a higher mean mathematics performance grade than the girls.

From these results, it could therefore be also forecasted that considering the downward trend in the GCE ordinary level mathematics performance of the students for the last three years, students' performance for the forth coming years could be horrible if nothing is done. Consequently, given the great importance mathematics has to an individual in particular, and to the development of any nation in general, it therefore becomes imperative that serious measures be put in place to ensure that there is an improvement in the mathematics performance of these students. This could be done by supplying more mathematics-related resources to schools (like textbooks, audio-visual ICT media and better trained mathematics teachers); giving more student incentives for the study of mathematics (especially to girls); tailoring the curriculum to be more in harmony with the needs, interests and abilities of the students; and, holding more mathematics seminars and workshops to update the knowledge and skills of the teachers.

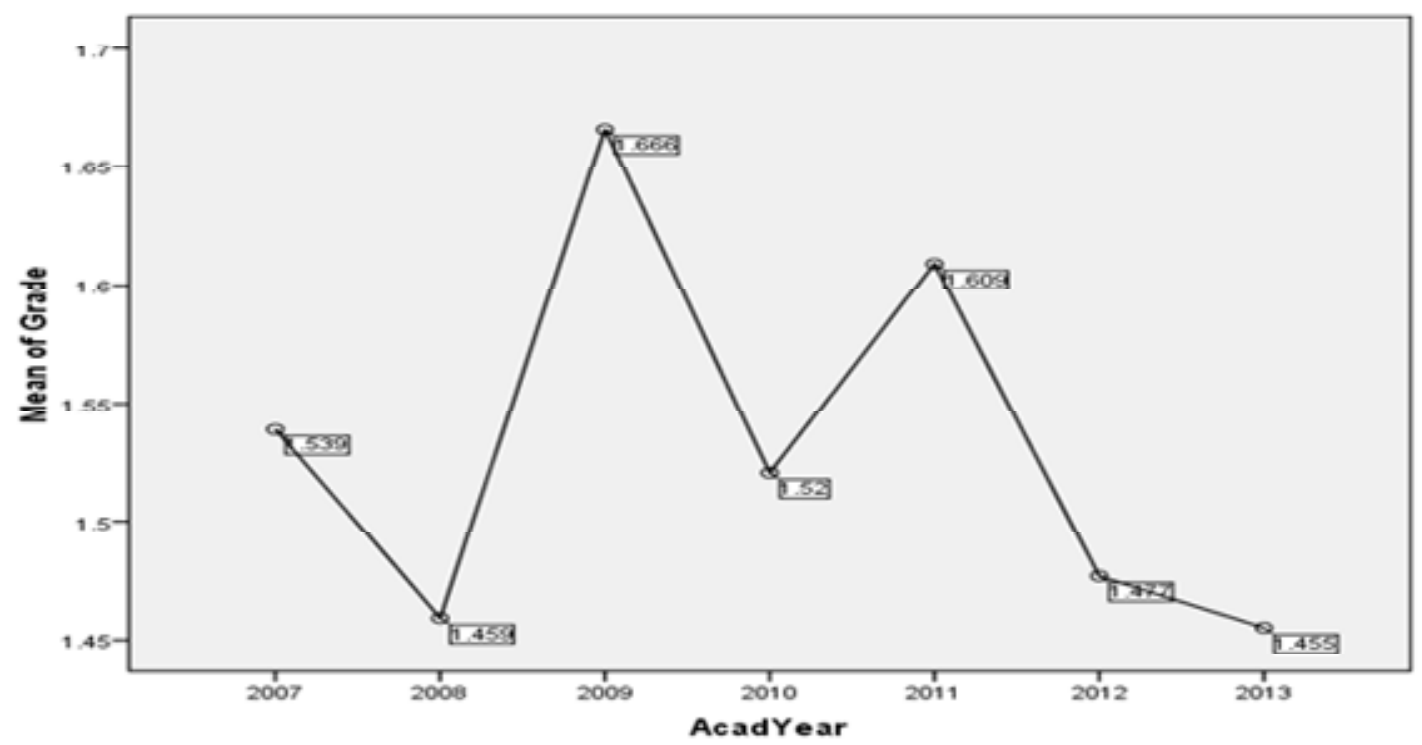

Figure 1: Means Plot showing the general trend in the GCE Ordinary Level Mathematics performance of students of the North West region of Cameroon across the years 2007 to 2013.

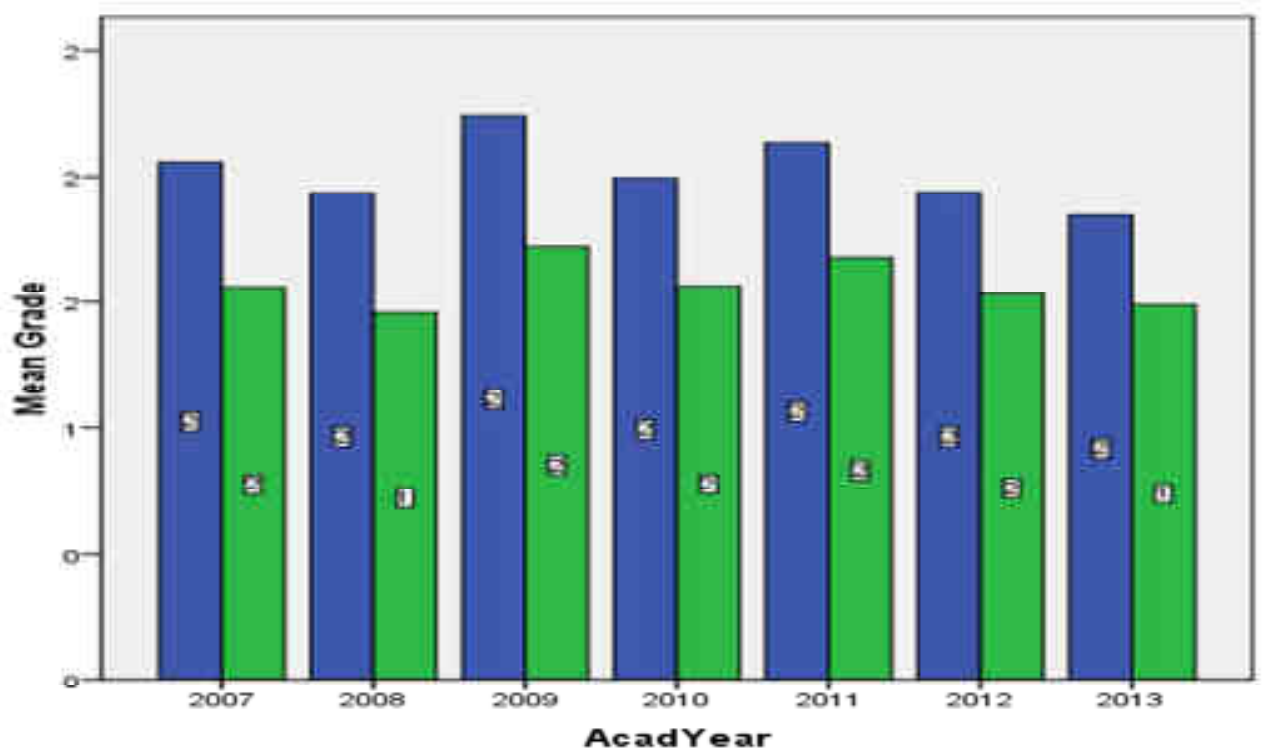

Figure 2: Bar chart showing the trend in the GCE Ordinary Level mathematics performance of male and female students of the North West Region of Cameroon over the years 2007 to 2013. 


\section{References}

Adams, R. J., \& Khoo, S.T. (1993). Quest- The interactive Test Analysis System. Hawthorn, Victoria: ACER. Affrasa, T. M., \& Keeves, J.P. (1999). Changes in students' mathematics achievement in Australian lower secondary schools over time. International Education Journal, 1 (1): 1-21.

Kellaghan, T., \& Greaney, V. (2001b). Using assessment to improve the quality of Education. Paris: UNESCO: International Institute for Educational Planning.

Kellaghan, T., \& Greaney, V. (2004). Monitoring performance: Assessment and examinations in Africa. Paris: Association for the Development of Education in Africa; Washington DC: World Bank.

Ker, H.W. (2013). Trend analysis on mathematics achievements: A comparative study using TIMSS data. Universal Journal of Educational Research, 1(3):200-213.

Konstantopoulos, S. (2006). Trends of school effects on student achievement: Evidence from NLS:72, HSB:82, and NELS:92. Teachers College Record, 108 (12): 2550-2581.

Mbong, J.N. (2009). Secondary school end-of-course examination crisis and management: The Cameroon Experience. Paper Presented at the $27^{\text {th }}$ Annual Conference of the Association for Educational Assessment in Africa (AEAA): Yaoundé, Cameroon (24 $4^{\text {th }}-28^{\text {th }}$ August, 2009).

Ngangeh, R. (2007). About Cameroon General Certificate of Education (GCE) Board. [online]. Available: http://www.camgce.org/ (July 8, 2011)

Onoshakpokaiye, E.O. (2010). Teachers' assessment of the difficulty levels of topics in Mathematics curriculum in Delta Senatorial District. Journal of Research in Education and Society, 1\&2(2\&3): 77-84.

Willett, J. B. (1997). Change, Measurement of. In J.P. Keeves (ed.), Educational Research, Methodology, and Measurement: An International Handbook, (second ed.), Oxford: Pergamon, pp. 327-334.

Wu, M.L. (2003). A comparison of PISA and TIMSS 2003 achievement results in mathematics. Paper presented at the AERA Annual Meeting, New York, March 2008. 
The IISTE is a pioneer in the Open-Access hosting service and academic event management. The aim of the firm is Accelerating Global Knowledge Sharing.

More information about the firm can be found on the homepage:

http://www.iiste.org

\section{CALL FOR JOURNAL PAPERS}

There are more than 30 peer-reviewed academic journals hosted under the hosting platform.

Prospective authors of journals can find the submission instruction on the following page: http://www.iiste.org/journals/ All the journals articles are available online to the readers all over the world without financial, legal, or technical barriers other than those inseparable from gaining access to the internet itself. Paper version of the journals is also available upon request of readers and authors.

\section{MORE RESOURCES}

Book publication information: http://www.iiste.org/book/

\section{IISTE Knowledge Sharing Partners}

EBSCO, Index Copernicus, Ulrich's Periodicals Directory, JournalTOCS, PKP Open Archives Harvester, Bielefeld Academic Search Engine, Elektronische Zeitschriftenbibliothek EZB, Open J-Gate, OCLC WorldCat, Universe Digtial Library, NewJour, Google Scholar

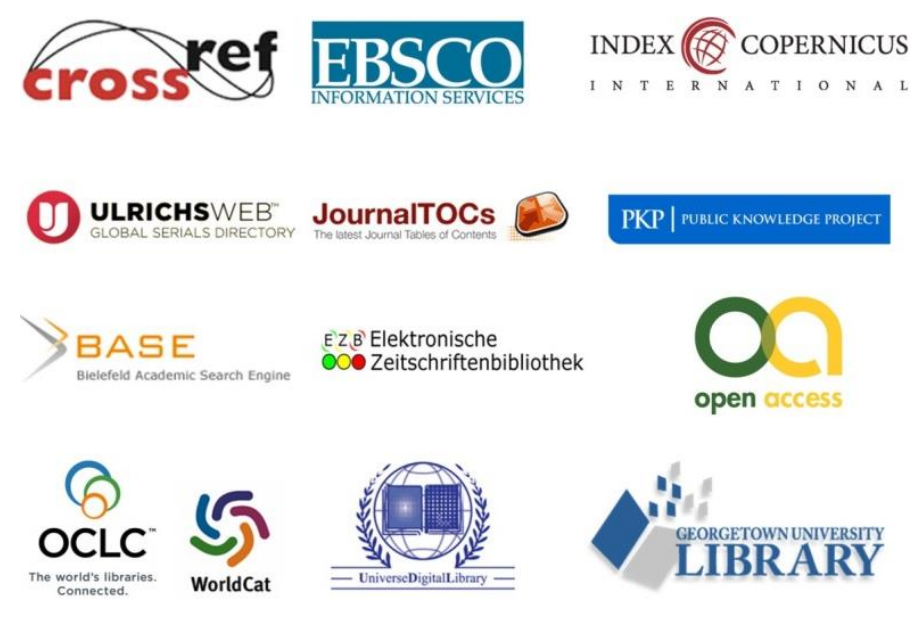

